\title{
Потенциометрическое определение метионина в щелочных растворах с помощью мембран Nafion и МФ-4СК, подвергшихся обработке и модификации
}

\author{
Титова Т.С. ${ }^{1}$, Паршина А.В. ${ }^{1}$, Янкина К.Ю. ${ }^{1}$, Сафронова Е.Ю. ${ }^{2}$, \\ Караванова Ю.А. ${ }^{2}$, Бобрешова О.В. \\ ${ }^{1}$ ФББОУ ВО «Воронежский государственный университет», Воронеж \\ ${ }^{2}$ Институт общей и неорганической химии имени Н.С. Курнакова РАН, Москва
}

Поступила в редакцию 20.03.2018 г.

DOI: https://doi.org/10.17308/sorpchrom.2018.18/494

Разработаны массивы перекрестно чувствительных ПД-сенсоров (аналитический сигнал - потенциал Доннана) на основе мембран Nafion и МФ-4СК, подвергшихся модификации и обработке, для определения анионов и цвиттерионов метионина совместно с катионами калия в щелочных растворах. Выявлено влияние кислотно-основных свойств и объемной доли наночастиц гидратирован-

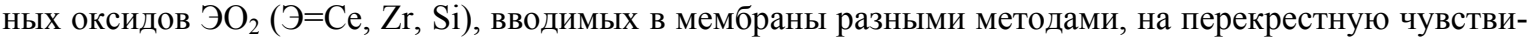
тельность ПД-сенсоров в исследуемых растворах. Выявлена зависимость чувствительности ПДсенсоров к анионам и цвиттерионам метионина от диффузионной проницаемости мембран, подвергшихся обработке при различных температуре и относительной влажности. Выбраны образцы, обеспечивающие достаточно низкие значения относительной погрешности и относительного стандартного отклонения определения анионов и цвиттерионов метионина совместно с катионами калия в диапазоне концентраций от $1.0 \cdot 10^{-4}$ до $5.0 \cdot 10^{-2} \mathrm{M}$, не смотря на переменные значения $\mathrm{pH}$ растворов, изменяющиеся в широком диапазоне (от 8 до 11).

Ключевые слова: потенциометрические сенсоры, перекрестная чувствительность, потенциал Доннана, перфторированные сульфокатионообменные мембраны, гибридные материалы, термическая обработка, гидротермальная обработка, метионин.

\section{Potentiometric determination of methionine in alkaline solutions by used Nafion and MF-4SC membranes treated and modified}

\author{
Titova T.S. ${ }^{1}$, Parshina A.V. ${ }^{1}$, Yankina K.Yu. ${ }^{1}$, \\ Safronova E.Yu. ${ }^{2}$, Karavanova Yu.A. ${ }^{2}$, Bobreshova O.V. ${ }^{1}$ \\ ${ }^{I}$ Voronezh State University, Voronezh \\ ${ }^{2}$ Kurnakov Institute of General and Inorganic Chemistry RAS, Moscow
}

\begin{abstract}
Methionine is an indispensable sulfur-containing amino acid used in the treatment of liver diseases and intoxication, as well as therapy for protein deficiency, atherosclerosis and diabetes mellitus. In industry methionine is produced by microbiological synthesis, isolation from natural raw materials (for example, from casein hydrolyzate) and chemical synthesis from 3-methylthiopropionic aldehyde, the last stage of which is alkaline hydrolysis. Therefore, the development of methods for the determination of methionine in an alkaline medium at the presence of alkali metal ions is actual. The important problem is the influence of medium $\mathrm{pH}$ on the accuracy of determination of amino acids due to their buffer properties, which determine the pres-
\end{abstract}

Tитова и др. / Сорбционные и хроматографические процессы. 2018. Т. 18. № 2 
ence of several ionic (including zwitterion) forms of analyte simultaneously in solution. For determination of amino acids in media with variable $\mathrm{pH}$ without the use of reagents, it is necessary to take into account its effect on the analytical signal. For this, promising is the use of a multisensory approach, in which the influence of all components of the test solution on the responses of an array of cross-sensitive sensors is accounted for by multidimensional calibration. The aim of the work was the development of cross-sensitive DP-sensors (the analytical signal is the Donnan potential) for the determination of methionine anions and zwitterions together with potassium cations in alkaline solutions by using Nafion and MF-4SC membranes, modified by oxides nanoparticles $\mathrm{EO}_{2}(\mathrm{E}=\mathrm{Ce}, \mathrm{Zr}, \mathrm{Si})$ and / or treated at different temperature and relative humidity.

The characteristics of DP-sensors were determined in the aqueous solutions containing methionine (Met) and $\mathrm{KOH}$ with different concentrations of components in the range from $1.0 \cdot 10^{-4}$ to $5.0 \cdot 10^{-2} \mathrm{M}(\mathrm{pH} 8$ 11). In the test solutions, methionine is predominantly in the form of anions (Met $\left.{ }^{-}\right)$and partly in the form of zwitterions $\left(\mathrm{Met}^{ \pm}\right)$. The initial Nafion and MF-4SC membranes, hybrid materials based on them, with hydrated oxides nanoparticles $\mathrm{EO}_{2}(\mathrm{E}=\mathrm{Ce}, \mathrm{Zr}, \mathrm{Si})$, and also unmodified and modified samples treated at the different temperature and relative humidity were used in DP-sensors. Nafion 115 membranes (Aldrich) were used, their modification was carried out in situ (sequential treatment by precursor solutions and ammonia solution to form oxides nanoparticles). Two types of MF-4SC membranes were used: obtained by extrusion from the polymer melt and obtained by casting from the polymer solution (Plastpolymer). MF- $4 \mathrm{SC}+\mathrm{EO}_{2}$ membranes were obtained by casting a polymer solution containing a precursor, followed by treatment with ammonia to produce oxides. Unmodified samples and hybrid materials based on them were treated. The treatment was carried out at $90-95^{\circ} \mathrm{C}$ and relative humidity of $60-95 \%$, and at the $100-140^{\circ} \mathrm{C}$ under hydrothermal conditions in contact with aqua.

The membranes pairs that provided a high sensitivity of DP-sensors to ions of opposite sign, response stability and minimal correlation between responses of sensor pairs were chosen for the simultaneously determination of methionine anions and zwitterions and potassium cations in alkaline solutions. The sensitivity of the DP-sensors to $\mathrm{K}^{+}$cations in Met $+\mathrm{KOH}$ solutions is high (from $39.42 \pm 0.18$ to $72.5 \pm 0.7 \mathrm{mV} / \mathrm{pC}$ ) for all test samples. The sensitivity of DP-sensors to $\mathrm{Met}^{-}, \mathrm{Met}^{ \pm}$ions increases with the introduction into the Nafion $_{\text {(extrusion) }}$ and MF-4SC (casting) membranes of $\mathrm{ZrO}_{2}$ and $\mathrm{SiO}_{2}$ oxides exhibiting acid properties at $\mathrm{pH}>7$. This is due to an increase in the concentration of bipolar ions and co-ions in the membrane due to the electrostatic repulsion of the pore walls and the surface of the deprotonated dopant. The influence of the volume

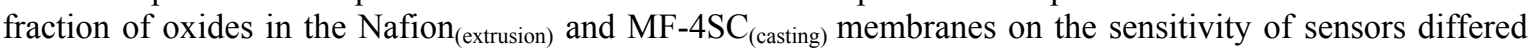
due to the structural features of these membranes. Treatment of $\mathrm{MF}-4 \mathrm{SC}_{\text {(extrusion) }}$ membranes in hydrothermal conditions at a temperature of $100-120^{\circ} \mathrm{C}$ provides an increase in the sensitivity of DP-sensors to Met, Met $^{ \pm}$ ions in proportion to the diffusion permeability of membranes (with a maximum of $23.4 \pm 0.8 \mathrm{mV} / \mathrm{pC}$ at $16.2 \cdot 10^{-8} \mathrm{~cm}^{2} / \mathrm{s}$ ). This is due to an increase of analyte concentration in membrane. Besides, the probability of interaction of charged amino groups of methionine zwitterions with the sulfo groups of the membrane increases by increasing the volume of the intra porous space and hydration of the membrane.

Arrays of cross-sensitive DP-sensors was developed to determine of methionine anions and zwitterions together with potassium cations in the alkaline solutions. Selected membrane samples provide sufficiently low values of the relative error and relative standard deviation of the analytes determination, despite variable $\mathrm{pH}$ values of solutions varying over a wide range ( $\mathrm{pH}$ from 8 to 11).

Keywords: potentiometric sensors cross sensitivity, Donnan potential, perfluorosulfonic membranes, hybrid materials, heat treatment, hydrothermal treatment, methionine.

\section{Введение}

Метионин - незаменимая серосодержащая аминокислота, применяемая при лечении заболеваний печени и интоксикации, а также терапии дефицита белка, атеросклероза и сахарного диабета. В промышленности метионин получают микробиологическим синтезом, выделением из природного сырья (например, из гидролизата казеина) и химическим синтезом из 3-метилтиопропионового альдегида, последней стадией которого является щелочной гидролиз. Поэтому разработка способов определения метионина в щелочной среде в присутствии ионов щелочных металлов является актуальной.

В настоящее время для определения метионина разрабатываются методы с различным принципом детектирования в зависимости от объектов и задач анализа. Для определения метионина в биологических средах (бактериальных клетках, сы- 
воротке крови и т.д.) описано использование высокоэффективной жидкостной хроматографии [1] и оптических биосенсоров на белка-регулятора транскрипции [2]. Для анализа лекарственных форм метионина предложена методика кулонометрического титрования [3]. Для определения метионина в модельных растворах и оценки его антиоксидантной активности разработан амперометрический угольнопастовый электрод, модифицированный пленкой из гексацианоферрата (II) рутения (III) [4]. Традиционно для контроля процессов сорбции и разделения аминокислот, в частности метионина [5], используют спектрофотометрический метод определения.

Важной проблемой является влияние $\mathrm{pH}$ среды на точность определения аминокислот из-за их буферных свойств, обусловливающих присутствие в растворе одновременно нескольких ионных (в том числе цвиттерионной) форм аналита. Для перевода аминокислот в форму, способную эффективно взаимодействовать с сорбентом [6] или титрантом [3, 7], как правило, используют растворы сильных неорганических кислот и оснований с достаточно высокой концентрацией. В спектрофотометрии для выбора оптимального значения рН предварительно исследуют зависимости оптической плотности растворов аминокислоты от $\mathrm{pH}$ [8], а в вольтамперометрии и амперометрии - зависимости значений потенциалов пика окисления и пикового тока окисления аминокислоты от рН $[9,10]$.

Для безреагентного определения аминокислот в средах с переменным $\mathrm{pH}$ необходимо учитывать его влияние на аналитический сигнал. Для этого перспективным представляется применение мультисенсорного подхода, в котором влияние всех компонентов исследуемого раствора на отклики массива перекрестно чувствительных сенсоров учитывается путем многомерной градуировки [11]. В работах [12-15] показана возможность потенциометрического определения некоторых аминокислот (на примере глицина, аланина, лейцина, гистидина, аргинина, аспарагиновой и глутаминовой кислот) в кислых и щелочных растворах с помощью перекрестно чувствительных ПД-сенсоров (аналитический сигнал - потенциал Доннана) на основе перфторированных сульфокатионообменных мембран. Оптимизация характеристик ПД-сенсоров достигалась за счет варьирования условий сорбции ионов, отличающихся знаком заряда, размером и свойствами функциональных групп, путем модификации мембран [12] и их обработки при различных условиях [13]. Показано, что присутствие в матрице мембран Nafion и МФ-4СК небольших количеств амфотерного диоксида циркония увеличивает чувствительность ПДсенсоров к катионам аминокислот и снижает ее к ионам гидроксония в кислых растворах, а в щелочных - увеличивает чувствительность к анионам аминокислот (на примере глицина, аланина, лейцина) [12]. Данный эффект был объяснен с позиции модели ограниченной эластичности стенок пор мембран [16], согласно которой концентрация диоксида циркония и взаимодействие его поверхностных групп (кислотно-основные свойства которых зависят от рН среды) с сульфо-группами мембраны определяют размеры внутрипорового пространства и распределение зарядов в нем. В работах $[13,14]$ показано, что термообработка мембран Nafion и МФ-4СК при различной относительной влажности позволяет существенно варьировать размеры пространства и содержание «электронейтрального» раствора внутри пор, что влияет на концентрацию определяемых и мешающих ионов, переходящих в мембрану при контакте сенсора с раствором аналита. Полученные результаты позволяют полагать, что варьирование кислотно-основных свойств допантов и применение подобной обработки к гибридным мембранам может открыть новые возможности для оптимизации характеристик ПД-сенсоров.

Tuтова и др. / Сорбционные и хроматографические процессы. 2018. Т. 18. № 2 
Целью работы являлась разработка перекрестно чувствительных ПД-сенсоров для определения анионов и цвиттерионов метионина совместно с катионами калия в щелочных растворах путем использования мембран Nafion и МФ-4СК, модифицированных наночастицами оксидов $Э \mathrm{O}_{2}$ (Э=Ce, $\mathrm{Zr}, \mathrm{Si}$ ) и/или обработанных при различных относительной влажности и температуре.

\section{Эксперимент}

Объекты исследования. Исследовали водные растворы, содержащие метионин (Met) и КОН с различным соотношением концентраций компонентов в диапазоне от $1.0 \cdot 10^{-4}$ до $5.0 \cdot 10^{-2} \mathrm{M}(\mathrm{pH} 8-11)$. В исследуемых растворах метионин присутствует преимущественно в форме анионов (Met') с диссоциированной карбоксильной группой и частично в форме цвиттерионов $\left(\mathrm{Met}^{ \pm}\right)$с диссоциированной карбоксильной и протонированной амино- группами.<smiles>CSCCC([NH3+])C(=O)[O-]</smiles>

$\mathrm{Met}^{-}$<smiles>CSCCC(N)C(=O)[O-]</smiles>

Мембраны. Исследовали исходные мембраны Nafion и МФ-4СК, гибридные материалы на их основе с наночастицами гидратированных оксидов ЭЭ ${ }_{2}(Э=\mathrm{Ce}, \mathrm{Zr}$, $\mathrm{Si})$, а также немодифицированные и модифицированные образцы, обработанные при различных температуре и относительной влажности.

Использовали мембраны Nafion 115 (Aldrich, толщина в сухом состоянии 130140 мкм, эквивалентная масса 1100, получены методом экструзии), их модификацию проводили методом in situ, т.е. последовательной обработкой растворами прекурсора и $10 \%$ раствором аммиака для формирования наночастиц оксидов. Использовали мембраны МФ-4СК, полученные двумя способами: экструзией из расплава полимера (ОАО «Пластполимер», ионообменная емкость - 1.0 ммоль/г, эквивалентная масса $1100)$ и отливкой в лабораторных условиях из $10 \%$ раствора полимера в диметилформамиде (ОАО «Пластполимер», ионообменная емкость 1.0 ммоль/г, эквивалентная масса 1100). Мембраны МФ-4СК+ЭО 2 получали отливкой из раствора полимера, содержащего прекурсор, с последующей обработкой аммиаком для получения оксидов. В качестве прекурсоров для получения оксидов $\mathrm{CeO}_{2}, \mathrm{ZrO}_{2}$ и $\mathrm{SiO}_{2}$ использовали водные растворы нитрата церия (AlfaAesar) и тетрахлорида циркония (Merck, $\geq 98 \%$ ) и раствор тетраэтоксисилана в метаноле (Aldrich, $98 \%$ ), соответственно. Все гибридные материалы для ПД-сенсоров были получены таким образом, что лишь $1 / 2$ длины пленки содержала допант. Конец этой части мембраны контактировал с исследуемым раствором в процессе эксперимента. Часть пленки, контактирующая с раствором сравнения, не была модифицирована. Полученные образцы кондиционировали для приведения к стандартным условиям (обработкой раствором $\mathrm{HCl}$ с последующей промывкой в деионизованной воде), затем переводили в $\mathrm{K}^{+}$-форму, выдерживая в течение 72 часов в $2 \mathrm{M}$ растворе $\mathrm{KCl}$ с последующей промывкой в деионизованной воде.

Обработке подвергали образцы в гидратированном состоянии в $\mathrm{K}^{+}$-форме: немодифицированные мембраны, полученные различными способами, и гибридные материалы на их основе. Обработку проводили в климатической камере Binder MKF115 при заданных температуре и влажности в течение 24 ч: при $90-95^{\circ} \mathrm{C}$ и относительной влажности (RH) 60-95 \%, а также при $100-140^{\circ} \mathrm{C}$ в гидротермальных условиях $\left(\mathrm{t}_{\text {го }}\right)$. 
Список исследуемых образцов мембран, их состав, способы получения, модификации и обработки, а также значения диффузионной проницаемости образцов, подвергшихся обработке, представлены в табл. 1, 2. Массовую долю оксидов в образцах, полученных методом in situ, определяли термогравиметрически (по соотношению массы мембраны в сухом состоянии и массы остатка после отжига при $600^{\circ} \mathrm{C}$ ). Отливкой получали образцы с заданной массовой долей оксидов (от 1 до 10 мас.\%) путем варьирования концентрации прекурсора в растворе полимера. Объемную долю оксида в мембране рассчитывали, исходя из его массы и плотности. Критерием эффективности обработки мембран при различных температуре и относительной влажности выбрали изменение диффузионной проницаемости через них $0.1 \mathrm{M}$ раствора $\mathrm{KCl}[13,14]$, поскольку данная величина косвенно характеризует размеры пространства и объема «электронейтрального» раствора внутри пор. Методика определения диффузионной проницаемости $0.1 \mathrm{M}$ раствора $\mathrm{KCl}$ через мембраны в деионизованную воду, а также влияние обработки и модификации на ее величину описаны в $[13,14]$.

Таблица 1. Состав и способ получения мембран Nafion + Э ${ }_{2}$ и МФ-4CК+ЭО

\begin{tabular}{|c|c|c|}
\hline Образец & Способ получения & Объемная доля допанта, \% \\
\hline Nafion & экструзия & - \\
\hline Nafion+3.9 мас. $\% \mathrm{CeO}_{2}$ & \multirow{3}{*}{ экструзия, in situ } & 1.1 \\
\hline Nafion +2.8 мас. $\% \mathrm{ZrO}_{2}$ & & 1.1 \\
\hline Nafion +0.6 мас. $\% \mathrm{SiO}_{2}$ & & 0.5 \\
\hline МФ-4СК & \multirow{9}{*}{ отливка } & - \\
\hline $\mathrm{M} \Phi-4 \mathrm{CK}+1$ мас. $\% \mathrm{CeO}_{2}$ & & 0.3 \\
\hline МФ-4СК+3 мас.\% $\mathrm{CeO}_{2}$ & & 0.9 \\
\hline $\mathrm{MФ-4CК+1} \mathrm{мас.} \% \mathrm{ZrO}_{2}$ & & 0.4 \\
\hline $\mathrm{MФ-4CК+3} \mathrm{мас.} \% \mathrm{ZrO}_{2}$ & & 1.2 \\
\hline $\mathrm{MФ-4CК+5} \mathrm{мас.} \% \mathrm{ZrO}_{2}$ & & 2.0 \\
\hline МФ-4СК+10 мас. $\% \mathrm{ZrO}_{2}$ & & 4.0 \\
\hline МФ-4CК+1 мас. $\% \mathrm{SiO}_{2}$ & & 0.8 \\
\hline $\mathrm{M} \Phi-4 \mathrm{CK}+3$ мас. $\% \mathrm{SiO}_{2}$ & & 2.5 \\
\hline
\end{tabular}

Таблица 2. Состав, способ получения и диффузионная проницаемость (Р, см²/c) мембран, термообработанных при различной относительной влажности $[13,14]$

\begin{tabular}{|c|c|c|}
\hline Образец & $\begin{array}{c}\text { Способ } \\
\text { получения }\end{array}$ & $\begin{array}{l}\mathrm{P} \cdot 10^{7}, \mathrm{~cm}^{2} / \mathrm{c} \\
(0.1 \mathrm{M} \mathrm{KCl})\end{array}$ \\
\hline Nafion & экструзия & 0.27 \\
\hline Nafion, $\mathrm{t}_{\mathrm{ro}}=120^{\circ} \mathrm{C}$ & \multirow{2}{*}{ экструзия } & 3.2 \\
\hline Nafion, $\mathrm{RH}=60 \%, \mathrm{t}=95^{\circ} \mathrm{C}$ & & 0.012 \\
\hline Nafion +1.9 мас. $\% \mathrm{ZrO}_{2}, \mathrm{t}_{\mathrm{ro}}=120^{\circ} \mathrm{C}$ & \multirow{2}{*}{ экструзия, in situ } & 2.1 \\
\hline Nafion +1.9 мас. $\% \mathrm{ZrO}_{2}, \mathrm{RH}=60 \%, \mathrm{t}=95^{\circ} \mathrm{C}$ & & 0.013 \\
\hline \multirow{2}{*}{ МФ-4СК } & экструзия & 0.562 \\
\hline & отливка & 0.41 \\
\hline $\mathrm{M \Phi}-4 \mathrm{CK}, \mathrm{RH}=60 \%, \mathrm{t}=90^{\circ} \mathrm{C}$ & \multirow{5}{*}{ экструзия } & 0.0067 \\
\hline $\mathrm{M \Phi}-4 \mathrm{CK}, \mathrm{RH}=95 \%, \mathrm{t}=90^{\circ} \mathrm{C}$ & & 0.132 \\
\hline $\mathrm{M} \Phi-4 \mathrm{CK}, \mathrm{t}_{\mathrm{ro}}=100^{\circ} \mathrm{C}$ & & 0.913 \\
\hline $\mathrm{M \Phi -4CK,} \mathrm{t}_{\mathrm{ro}}=120^{\circ} \mathrm{C}$ & & 1.62 \\
\hline $\mathrm{M} \Phi-4 \mathrm{CK}, \mathrm{t}_{\mathrm{ro}}=140^{\circ} \mathrm{C}$ & & 2.27 \\
\hline $\mathrm{M \Phi -4CK,} \mathrm{RH=60 \% ,} \mathrm{t}=95^{\circ} \mathrm{C}$ & \multirow{2}{*}{ отливка } & 0.12 \\
\hline $\mathrm{M} \Phi-4 \mathrm{CK}, \mathrm{t}_{\mathrm{rO}}=120^{\circ} \mathrm{C}$ & & 35 \\
\hline
\end{tabular}

Tuтова и др. / Сорбционные и хроматографические процессы. 2018. Т. 18. № 2 
Методы исследования. Электрохимическая ячейка для оценки сенсорных свойств мембран разного состава включала набор (до 8 шт.) перекрестно чувствительных ПД-сенсоров на их основе, стеклянный электрод (ООО «Эконикс-Эксперт», ЭС-10301/4) для контроля $\mathrm{pH}$ исследуемого раствора, электрод сравнения (ООО «Эконикс-Эксперт», ЭСр-10103) и многоканальный потенциометр. В электрохимической ячейке для совместного определения ионов метионина и калия число ПД-сенсоров снижалось до двух. Электрохимическая цепь для оценки отклика ПДсенсора с гибридной мембраной описывается выражением (1), причем расстояние между раствором сравнения сенсора и исследуемым раствором соответствует длине мембраны, а не ее толщине как в классических мембранных электродах.

$\mathrm{Ag}|\mathrm{AgCl}, 1 \mathrm{M} \mathrm{KCl}|$ мембрана / мембрана+ ЭО $2 \mid$ исследуемый раствор $\mid$ нас. $\mathrm{KCl}$,

$$
\mathrm{AgCl} \mid \mathrm{Ag} \text {. }
$$

Для характеризации ПД-сенсоров определяли время, дрейф и дисперсию $\left(\mathrm{s}^{2}, \mathrm{MB}^{2}\right)$ отклика, чувствительность сенсоров, относительную погрешность $\left(\delta=\left(c_{\text {эксn }}\right.\right.$

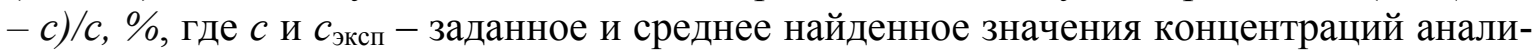
та) и относительное стандартное отклонение $\left(s_{r}=s / c_{\text {эксn }}, \%\right)$ определения аналитов в исследуемых растворах. Значения времени и дрейфа отклика сенсоров определяли хронопотенциометрически. Дисперсию отклика сенсоров и относительное стандартное отклонение определения аналитов оценивали в условиях воспроизводимости. Относительную погрешность определения аналитов оценивали методом «введенонайдено». Для оценки перекрестной чувствительности ПД-сенсоров в растворах $\mathrm{Met}+\mathrm{KOH}$ выбраны градуировочные уравнения вида (2).

$$
\Delta \varphi_{D}=b_{0}+b_{1} \cdot p K+b_{2} \cdot p H+b_{3} \cdot p M e t,
$$

где $\Delta \varphi_{D}$ - величина отклика ПД-сенсора, $\mathrm{mB} ; p K$ - отрицательный десятичный логарифм молярной концентрации катионов $K^{+} ; p M e t-$ отрицательный десятичный логарифм суммарной молярной концентрации анионов Met и цвиттерионов $\mathrm{Met}^{ \pm}$; $b_{0}$ - свободный член градуировочного уравнения, $\mathrm{MB} ; b_{i}-$ коэффициенты чувствительности ПД-сенсора к соответствующим ионам, $\mathrm{MB} / \mathrm{pC}$. Для выявления возможных систематических ошибок и доказательства правильности выбора градуировочного уравнения оценивали его адекватность по $F$-критерию Фишера. Значимость коэффициентов уравнения оценивали по $t$-критерию Стьюдента. Корреляцию между откликами пар сенсоров оценивали по $r$-критерию Пирсона.

\section{Обсуждение результатов}

Для совместного определения анионов, цвиттерионов метионина и катионов калия в щелочных растворах выбирали пары мембран, обеспечивающие высокую чувствительность ПД-сенсоров к ионам противоположного знака, стабильность отклика и минимальную корреляцию между откликами пар сенсоров.

Чувствительность ПД-сенсоров на основе катионообменной мембраны к различным ионам определяется рядом факторов: возможностью их перехода в мембрану при установлении квазиравновесия на границе мембрана/раствор аналита, их концентрацией в мембране и доступностью функциональных групп мембраны и допанта для взаимодействия с ними. Поэтому исследовали влияние кислотно-основных

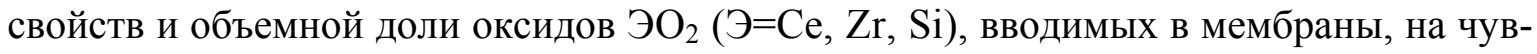
ствительность ПД-сенсоров к катионам и анионам в растворах Met+KOH. Кроме того, исследовали зависимость чувствительности ПД-сенсоров к катионам и анионам от диффузионной проницаемости мембран, поскольку ее значения косвенно характеризуют объем внутрипорового пространства (который должен коррелировать с объемом «электронейтрального» раствора и концентрацией коионов в мембране).

Tuтова и др. / Сорбционные и хроматографические процессы. 2018. Т. 18. № 2 
Чувствительность ПД-сенсоров к катионам $\mathrm{K}^{+}$в растворах Met+KOH является высокой (от $39.42 \pm 0.18$ до $72.5 \pm 0.7 \mathrm{mB} / \mathrm{pC}$ ) для всех исследуемых образцов (рис. 1, 2).

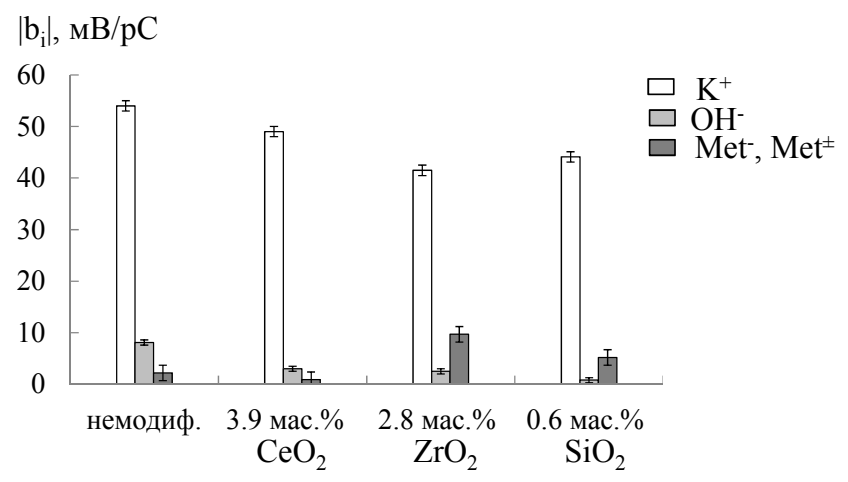

a

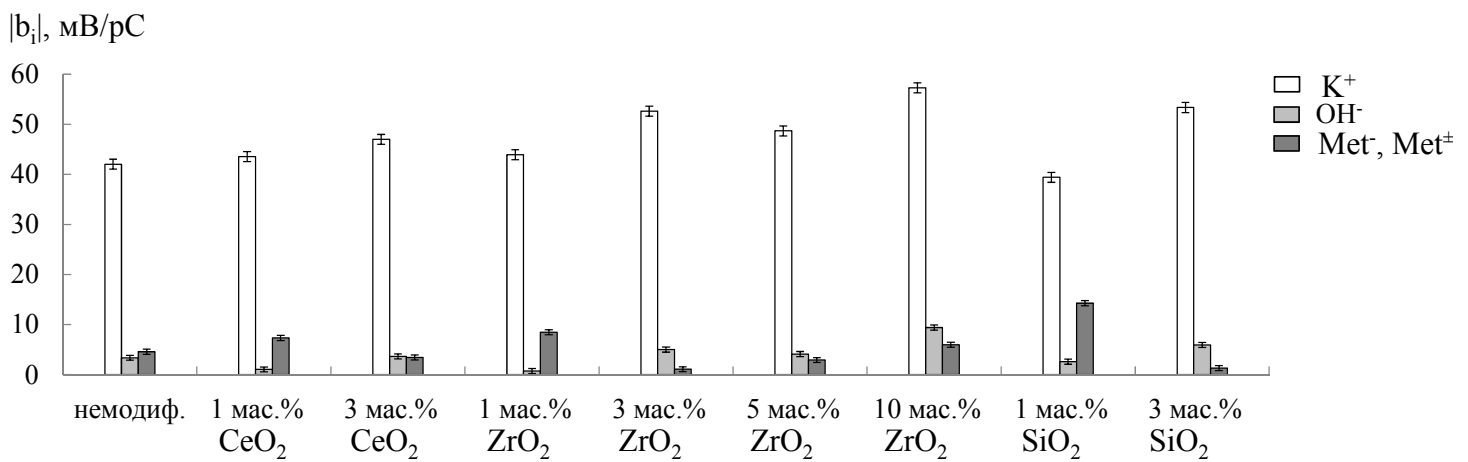

6

Рис. 1. Коэффициенты чувствительности ПД-сенсоров на основе мембран

Nafion $+Э \mathrm{O}_{2 \text { (экструзия, in situ) }}$ (a) и МФ-4СК $+Э \mathrm{O}_{2 \text { (отливка) }}($ б) к катионам и анионам в растворах Met $+\mathrm{KOH}$. Образцы мембран расположены в порядке возрастания кислотных свойств допанта

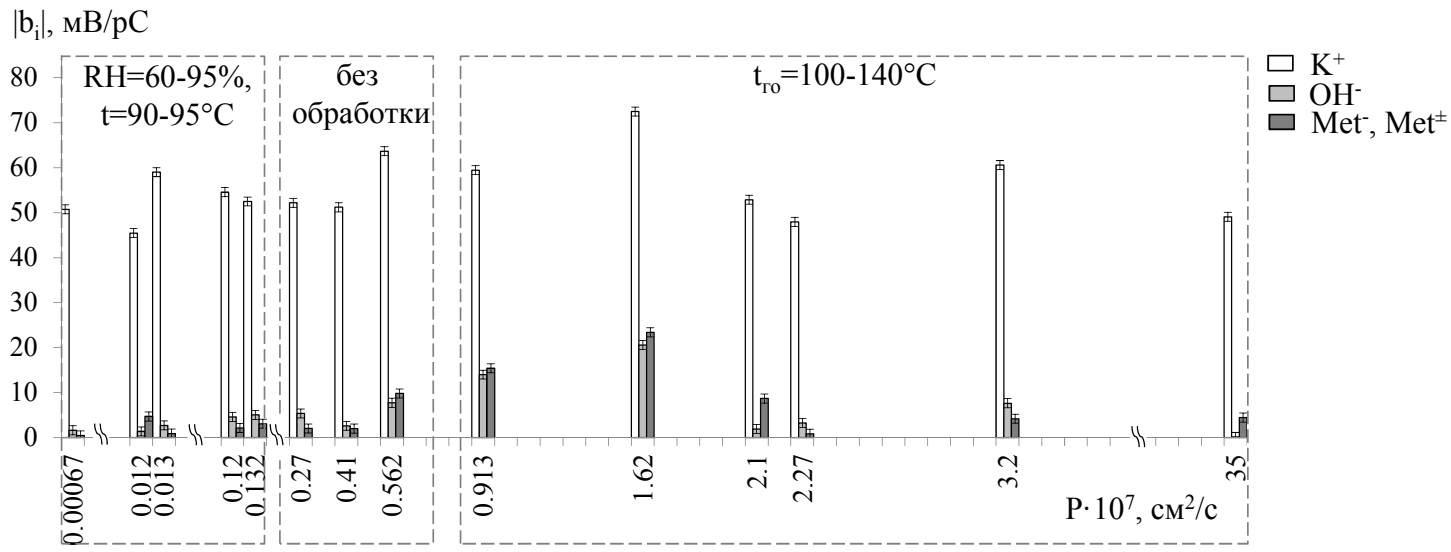

Рис. 2. Зависимость коэффициентов чувствительности ПД-сенсоров к катионам и анионам в растворах $\mathrm{Met}+\mathrm{KOH}$ от диффузионной проницаемости мембран

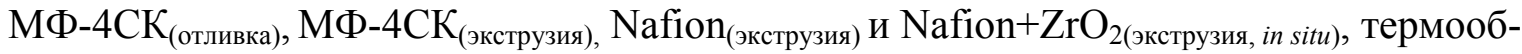
работанных при различной относительной влажности

Чувствительность ПД-сенсоров к ионам Met', $\mathrm{Met}^{ \pm}$увеличивается при введе-

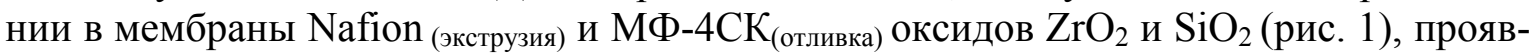
ляющих при $\mathrm{pH}>7$ кислотные свойства. Это связано с возрастанием концентрации необменно сорбированных биполярных ионов и коионов в мембране из-за электро- 
статического отталкивания стенок пор и поверхности депротонорованного допанта. Наибольшая чувствительность ПД-сенсоров к ионам $\operatorname{Met}^{-} \operatorname{Met}^{ \pm}(8.5 \pm 0.2$ и $14.3 \pm 0.2 \mathrm{mB} / \mathrm{pC}$, рис. 1 б) достигается для образцов на основе мембран МФ$4 \mathrm{CK}_{\text {(отливка) }}$ с невысокой объемной долей $\mathrm{ZrO}_{2}$ и $\mathrm{SiO}_{2}(0.4$ об.\% и 0.8 об.\%, табл. 1). Увеличение объема частиц допантов в мембранах МФ-4СК (отливка) приводит к снижению чувствительности сенсоров к ионам Met, $\mathrm{Met}^{ \pm}$до значений, соизмеримых с таковыми для немодифицированного образца. Тогда как большая чувствительность ПД-сенсоров к ионам Met-, Met $^{ \pm}$для образцов на основе мембран Nafion (экструзия) достигается для более объемного $\mathrm{ZrO}_{2}$, не смотря на его менее выраженные кислотные свойства, чем у $\mathrm{SiO}_{2}$. Это может быть обусловлено особенностями получения материалов на основе мембран МФ-4СК (отливка), обусловливающими больший размер пор и менее упорядоченную структуру, по сравнению с материалами на основе мембран Nafion (экструзия).

В результате обработки мембран МФ-4СК (экструзия) в гидротермальных условиях при температуре $100-120^{\circ} \mathrm{C}$ чувствительность ПД-сенсоров к ионам Met ${ }^{-} \mathrm{Met}^{ \pm}$возрастает пропорционально диффузионной проницаемости мембран (достигая максимума $23.4 \pm 0.8 \mathrm{mB} / \mathrm{pC}$ при диффузионной проницаемости $P=16.2 \cdot 10^{-8} \mathrm{~cm}^{2} / \mathrm{c}$ для образца МФ-4СК (экстузия), $\mathrm{t}_{\text {го }}=120^{\circ} \mathrm{C}$, рис. 2). Это обусловлено увеличением концентрации аналита в мембране. Кроме того, при увеличении объема внутрипорового пространства и гидратации мембраны возрастает вероятность взаимодействия заряженных аминогрупп цвиттерионов метионина с сульфогруппами мембраны. Дальнейшее увеличение температуры гидротермальной обработки мембран (до $140^{\circ} \mathrm{C}$ для

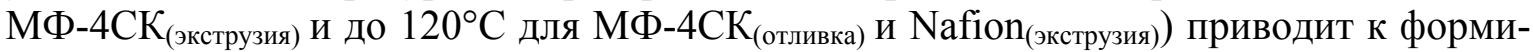
рованию в мембране объемных полостей, заполненных контактирующим с мембраной раствором. При этом близость составов внешнего и внутреннего раствора мембраны обусловливает снижение чувствительности сенсора, как к анионам, так и к катионам. Снижение же диффузионной проницаемости мембран $\leq 1.32 \cdot 10^{-8} \mathrm{~cm}^{2} / \mathrm{c}$ в результате их обработки при относительной влажности $<100 \%$ обеспечивает незначимую чувствительность ПД-сенсоров к ионам $\mathrm{Met}^{-}, \mathrm{Met}^{ \pm}(\leq 3 \mathrm{MB} / \mathrm{pC})$. Это обусловлено удалением необменно сорбированных ионов из мембраны.

Таблица 3. Характеристики систем ПД-сенсоров (а) и (б) для определения ионов метионина и калия при рН 8-11 в диапазоне концентраций от $1.0 \cdot 10^{-4}$ до $5.0 \cdot 10^{-2} \mathrm{M}(\mathrm{n} \geq 5$, $\mathrm{p}=0.95)$

\begin{tabular}{|c|c|c|c|c|}
\hline Система ПД-сенсоров & \multicolumn{2}{|c|}{ (a) } & \multicolumn{2}{|c|}{ (б) } \\
\hline Способ получения МФ-4СК & \multicolumn{2}{|c|}{ экструзия } & \multicolumn{2}{|c|}{ отливка } \\
\hline $\begin{array}{l}\text { Модификация/обработка } \\
\text { МФ-4СК }\end{array}$ & $\begin{array}{c}90^{\circ} \mathrm{C} \\
\mathrm{RH}=95 \%\end{array}$ & $\mathrm{t}_{\mathrm{ro}}=120^{\circ} \mathrm{C}$ & 10 мас. $\% \mathrm{ZrO}_{2}$ & 1 мас. $\% \mathrm{SiO}_{2}$ \\
\hline Время отклика, мин & $<1$ & $<1$ & $<1$ & $<1$ \\
\hline Дрейф, мВ/ч & 1.0 & 8 & 3 & 2 \\
\hline $\mathrm{s}^{2}, \mathrm{MB}^{2}$ & 74 & 14 & 9 & 10 \\
\hline Чувствительность к $\mathrm{K}^{+}, \mathrm{mB} / \mathrm{pC}$ & $50.7 \pm 0.7$ & $72.5 \pm 0.7$ & $57.3 \pm 0.3$ & $39.42 \pm 0.18$ \\
\hline 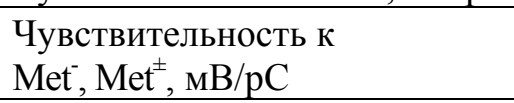 & $0.5 \pm 0.8$ & $23.4 \pm 0.8$ & $5.98 \pm 0.02$ & $14.283 \pm 0.018$ \\
\hline$\delta\left(\mathrm{K}^{+}\right), \%$ & \multicolumn{2}{|c|}{$0.2-14$} & \multicolumn{2}{|c|}{$2-15$} \\
\hline$\delta\left(\right.$ Met $\left.^{-}, \operatorname{Met}^{ \pm}\right), \%$ & \multicolumn{2}{|c|}{$1.2-9$} & \multicolumn{2}{|c|}{$2-14$} \\
\hline $\mathrm{S}_{\mathrm{r}}\left(\mathrm{K}^{+}\right), \%$ & \multicolumn{2}{|c|}{$0.10-14$} & \multicolumn{2}{|c|}{$1.8-9$} \\
\hline $\mathrm{s}_{\mathrm{r}}\left(\mathrm{Met}^{-}, \mathrm{Met}^{ \pm}\right), \%$ & \multicolumn{2}{|c|}{$5-16$} & \multicolumn{2}{|c|}{$5-9$} \\
\hline
\end{tabular}

Характеристики оптимизированных систем ПД-сенсоров для определения ионов метионина и калия в щелочных растворах в диапазоне концентраций 
от $1.0 \cdot 10^{-4}$ до $5.0 \cdot 10^{-2} \mathrm{M}$ при $(\mathrm{n} \geq 5, \mathrm{p}=0.95)$ представлены в табл. 3. Выбранные образцы мембран обеспечивают достаточно низкие значения относительной погрешности и относительного стандартного отклонения определения аналитов не смотря на переменные значения рН растворов, изменяющиеся в широком диапазоне (от 8 до 11).

\section{Заключение}

Выявлено влияние кислотно-основных свойств и объемной доли наночастиц

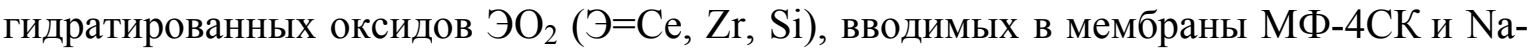
fion разными методами, на перекрестную чувствительность ПД-сенсоров (аналитический сигнал - потенциал Доннана) в щелочных растворах метионина. Выявлена зависимость чувствительности ПД-сенсоров к анионам и цвиттерионам метионина от диффузионной проницаемости мембран МФ-4СК, Nafion и $\mathrm{Nafion}+\mathrm{ZrO}_{2}$, подвергшихся обработке при различных температуре и относительной влажности. Разработаны массивы перекрестно чувствительных ПД-сенсоров для определения анионов и цвиттерионов метионина совместно с катионами калия в растворах с переменным рН (от 8 до 11) в диапазоне концентраций от $1.0 \cdot 10^{-4}$ до $5.0 \cdot 10^{-2} \mathrm{M}$.

\section{Список литературы}

1. Deáková Z., Ďuračková Z., Armstrong D.W., Lehotay J. // Journal of Chromatography A. 2015. Vol. 1408. pp. 118-124.

2. Mustafi N., Grünberger A., Kohlheyer D., Bott M. et al. // Metabolic engineering. 2012. Vol. 14, №. 4. pp. 449-457.

3. Зиятдинова Г.К., Григорьева Л. В., Будников, Г.К. // Журнал аналитической химии. 2007. Т. 62. № 12. С. 1304-1308.

4. Шайдарова Л.Г., Зиганшина С.А., Тихонова Л.П., Будников Г.К. // Журнал аналитической химии. 2003. Т. 58. № 12. С. 12771284.

5. Григорова Е.В., Бондарева Л.П., Корниенко Т.С., Овсянникова Д.В. // Сорбичионные u хроматографические проиессы. 2010. Т. 10. Вып. 5. С. 749-753.

6. Wang Y.Q., Ye D.Q., Zhu B.Q., Wu G.F., Duan C.Q. // Food chemistry. 2014. Vol. 163. pp. 6-15.

7. Варыгина О.В., Чернова Р.К., Петрович М.В. // Изв. Сарат. ун-та. Нов. сер. Сер. Химия. Биология. Экология. 2016. Т. 16, Вып. 2. C. $125-130$.

8. Ojeda C.B., Rojas F.S. // Microchemical Journal. 2013. Vol. 106. pp. 1-16.

\section{References}

1. Deáková Z., Ďuračková Z., Armstrong D.W., Lehotay J., Journal of Chromatography A, 2015, Vol. 1408, pp. 118-124. DOI: 10.1016/j.chroma.2015.07.009.
9. Mirceski V., Gulaboski R., Lovric M., Bogeski I. et al. // Electroanalysis. 2013. Vol. 25. No. 11. pp. 2411-2422.

10. Shrestha S., Mascarenhas R J., D'Souza O.J., Satpati A.K. et al. // Journal of Electroanalytical Chemistry. 2016. Vol. 778. pp. 32-40.

11. Lvova L., Gonçalves C.G., Petropoulos K., Micheli L. et al. // Biosensors and Bioelectronics . 2016. Vol. 80. pp. 154-160.

12.Паршина А.В., Титова Т.С., Сафронова Е.Ю., Бобрешова О.В. и др. // Журнал аналитической химии. 2016. Т. 71. № 3. С. 272281.

13. Сафронова Е.Ю., Паршина А.В., Рыжкова Е.А., Сафронов Д.В. и др. // Мембраны и мембранные технологии. 2017. Т. 7. № 6. C. 432-440.

14.Safronova E., Safronov D., Lysova A., Parshina A.et al. // Sensors and Actuators B: Chemical. 2017. Vol. 240. pp. 1016-1023.

15.Safronova E., Parshina A., Kolganova T., Bobreshova O. et al. // Journal of Electroanalytical Chemistry. 2018. Vol. 816. pp. 21-29.

16.Ярославцев А.Б., Караванова Ю.А., Сафронова Е.Ю. // Мембраны и мембранные технологии. 2011. Т. 1 № 1. С. 3-10.

2. Mustafi N., Grünberger A., Kohlheyer D., Bott M. et al., Metabolic engineering, 2012, Vol. 14, No 4, pp. 449-457. DOI: 10.1016/j.ymben.2012.02.002. 
3. Ziyatdinova G.K., Grigor'eva L.V., Budnikov G.K., Journal of Analytical Chemistry, 2007, Vol. 62, No 12, pp. 1176-1179. DOI: 10.1134/S1061934807120143.

4. Shaidarova L.G., Ziganshina S.A., Tikhonova L.N., Budnikov G.K., Journal of Analytical Chemistry, 2003, Vol. 58, No 12, pp. 11441150.

DOI:

10.1023/B:JANC.0000008953.67244.c2.

5. Grigorova E.V., Bondareva L.P., Kornienko T.S., Ovsyannikova D.V., Sorbtsionnye $i$ khromatograficheskie protsessy, 2010, Vol. 10, No 5, pp. 749-753.

6. Wang Y.Q., Ye D.Q., Zhu B.Q., Wu G.F. et al., Food chemistry, 2014, Vol. 163, pp. 6-15. DOI: 10.1016/j.foodchem.2014.04.064.

7. Varyigina O.V., Chernova R.K., Petrovich M.V., Izv. Sarat. un-ta. Nov. ser. Ser. Himiya. Biologiya. Ekologiya, 2016, Vol. 16, No 2, pp. 125-130.

8. Ojeda C.B., Rojas F.S., Microchemical Journal, 2013, Vol. 106, pp. 1-16. DOI: 10.1016/j.microc.2012.05.012.

9. Mirceski V., Gulaboski R., Lovric M., Bogeski I. et al., Electroanalysis, 2013, Vol. 25, No 11. pp. 2411-2422. DOI: 10.1002/elan.201300369.

Титова Татьяна Сергеевна - аспирант, кафедра аналитической химии, Воронежский государственный университет, Воронеж

Паршина Анна Валерьевна - д.х.н., доцент, кафедра аналитической химии, Воронежский государственный университет, Воронеж, parshina_ann@mail.ru

Я̆нкина Кристина Юрьевна - к.Х.н., старший научный сотрудник, кафедра аналитической химии, Воронежский государственный университет, Воронеж

Сафронова Екатерина Юрьевна - к.Х.н., старший научный сотрудник, Лаборатория ионики функциональных материалов, Институт общей и неорганической химии имени Н.С. Курнакова РАН, Москва

Караванова Юлия Алексеевна - к.Х.н., старший научный сотрудник, Лаборатория ионики функциональных материалов, Институт общей и неорганической химии имени Н.С. Курнакова РАН, Москва

Бобрешова Ольга Владимировна - д.х.н., профессор, главный научный сотрудник, кафедра аналитической химии, Воронежский государственный университет, Воронеж
10.Shrestha S., Mascarenhas R J., D'Souza O.J., Satpati A.K. et al., Journal of Electroanalytical Chemistry, 2016, Vol. 778, pp. 32-40. DOI: 10.1016/j.jelechem.2016.08.010.

11. Lvova L., Gonçalves C.G., Petropoulos K., Micheli L. et al., Biosensors and Bioelectronics, 2016, Vol. 80, pp. 154-160. DOI: 10.1016/j.bios.2016.01.050.

12.Parshina A.V., Titova T.S., Safronova E.Yu., Bobreshova O.V et al., Journal of Analytical Chemistry, 2016,Vol. 71, No 3, pp. 259268. DOI: $10.1134 / \mathrm{S} 1061934816030102$.

13.Safronova E.Yu., Parshina A.V., Ryzhkova E.A., Safronov D.V. et al., Petroleum Chemistry, 2017, Vol. 57, No 13, pp. 1188-1195. DOI: $0.1134 / \mathrm{S} 0965544117130096$.

14.Safronova E., Safronov D., Lysova A., Parshina A. et al., Sensors and Actuators B: Chemical, 2017, Vol. 240, pp. 1016-1023. DOI: 10.1016/j.snb.2016.09.010.

15.Safronova E., Parshina A., Kolganova T., Bobreshova O. et al.,/ Journal of Electroanalytical Chemistry, 2018, Vol. 816, pp. 21-29. DOI: 10.1016/j.jelechem.2018.03.028.

16. Yaroslavtsev A.B. Karavanova Yu.A., Safronova E.Yu. , Petroleum Chemistry, 2011, Vol. 1, No 1, pp. 3-10. DOI: 10.1134/S0965544111070140.

Titova Tatyana S. - postgraduate student, department of analytical chemistry, Voronezh State University, Voronezh

Parshina Anna V. - Dr.Sci. (Chemistry), docent, department of analytical chemistry, Voronezh State University, Voronezh, parshina_ann@mail.ru

$\bar{Y}$ ankina Kristina Yu. - Ph.D. (Chemistry), senior researcher, department of analytical chemistry, Voronezh State University, Voronezh

Safronova Ekaterina Yu. - Ph.D. (Chemistry), senior researcher, Laboratory of Ionics of Functional Materials, Kurnakov Institute of General and Inorganic Chemistry RAS, Moscow

Karavanova Yulia A. - Ph.D. (Chemistry), senior researcher, Laboratory of Ionics of Functional Materials, Kurnakov Institute of General and Inorganic Chemistry RAS, Moscow

Bobreshova Olga V. - Dr.Sci. (Chemistry), professor, chief scientific researcher, department of analytical chemistry, Voronezh State University, Voronezh 